\title{
Correction to: Data Mining and Performance Prediction of Flexible Road Pavement Using Fuzzy Logic Theory: A Case of Nigeria
}

Adekunle Taiwo Olowosulu, Jibrin Mohammed Kaura, Abdulfatai Adinoyi Murana, and Paul Terkumbur Adeke

\section{Correction to:}

Chapter "Data Mining and Performance Prediction of Flexible Road Pavement Using Fuzzy Logic Theory:

A Case of Nigeria" in: H. Shehata and S. El-Badawy (Eds.): Sustainable Issues in Infrastructure Engineering, SUCI, https://doi.org/10.1007/978-3-030-62586-3_11

The original version of the book was inadvertently published with an error in Table 5 of Chapter 11, which has now been corrected as follows:

Table 5. Development of fuzzy sets for attributes

\begin{tabular}{|c|c|c|c|c|}
\hline $\mathrm{S} / \mathrm{N}$ & Parameters & Classifications & Limits & Ranges of FMF \\
\hline \multirow[t]{5}{*}{1.} & \multirow{5}{*}{$\begin{array}{l}\text { Initial pavement condition } \\
\text { (IPC) }\end{array}$} & Very poor & $<25$ & {$\left[\begin{array}{lll}0 & 15 & 25\end{array}\right]$} \\
\hline & & Poor & $25-45$ & {$\left[\begin{array}{lll}20 & 35 & 50\end{array}\right]$} \\
\hline & & Fair & $46-65$ & {$\left[\begin{array}{lll}40 & 50 & 65\end{array}\right]$} \\
\hline & & Good & $66-81$ & {$\left[\begin{array}{lll}60 & 70 & 87\end{array}\right]$} \\
\hline & & Excellent & $>81$ & {$\left[\begin{array}{lll}80 & 90 & 100\end{array}\right]$} \\
\hline \multirow[t]{4}{*}{2.} & \multirow[t]{4}{*}{ Age of pavement (years) } & New & $<2$ & {$\left[\begin{array}{lll}0 & 1 & 3\end{array}\right]$} \\
\hline & & Recent & $2-5$ & {$\left[\begin{array}{lll}2 & 5 & 7\end{array}\right]$} \\
\hline & & Old & $6-12$ & {$\left[\begin{array}{lll}6 & 9 & 13\end{array}\right]$} \\
\hline & & Very old & $>12$ & {$\left[\begin{array}{lll}12 & 16 & 20\end{array}\right]$} \\
\hline \multirow[t]{4}{*}{3.} & \multirow[t]{4}{*}{ Truck load (veh/day) } & Low & $<200$ & {$\left[\begin{array}{lll}0 & 125 & 280\end{array}\right]$} \\
\hline & & Medium & $200-1000$ & {$\left[\begin{array}{lll}195 & 600 & 1000\end{array}\right]$} \\
\hline & & High & $1001-2000$ & {$\left[\begin{array}{llll}850 & 1400 & 2000\end{array}\right]$} \\
\hline & & Very high & $>2000$ & {$\left[\begin{array}{llll}1700 & 2000 & 2500\end{array}\right]$} \\
\hline
\end{tabular}

The updated version of this chapter can be found at https://doi.org/10.1007/978-3-030-62586-3_11 
Table 5. (continued)

\begin{tabular}{|c|c|c|c|c|}
\hline $\mathrm{S} / \mathrm{N}$ & Parameters & Classifications & Limits & Ranges of FMF \\
\hline \multirow[t]{4}{*}{4.} & \multirow[t]{4}{*}{$\mathrm{M}_{\mathrm{R}}$ of subgrade soil $\left(\mathrm{kg} / \mathrm{m}^{2}\right)$} & Low & $<0.7 \times 10^{7}$ & $\begin{array}{l}{\left[\begin{array}{ll}0 & 0.4 \\
0.75\end{array}\right] \times 10^{7}}\end{array}$ \\
\hline & & Medium & $\begin{array}{l}{[0.7-} \\
1.3] \times 10^{7}\end{array}$ & $\begin{array}{l}{\left[\begin{array}{ll}0.6 & 1.0 \\
1.425] \times 10^{7}\end{array}\right.}\end{array}$ \\
\hline & & High & $\begin{array}{l}{[1.3-} \\
2.1] \times 10^{7}\end{array}$ & $\begin{array}{l}{[1.21 .8} \\
2.4] \times 10^{7}\end{array}$ \\
\hline & & Very high & $>2.1 \times 10^{7}$ & $\begin{array}{l}{[2.02 .48} \\
3.0] \times 10^{7}\end{array}$ \\
\hline \multirow[t]{4}{*}{5.} & \multirow[t]{4}{*}{ Temperature $\left({ }^{\circ} \mathrm{C}\right)$} & Low & $<20$ & {$\left[\begin{array}{lll}0 & 10 & 20\end{array}\right]$} \\
\hline & & Medium & $20-35$ & {$\left[\begin{array}{lll}15 & 25 & 35\end{array}\right]$} \\
\hline & & High & $36-45$ & {$\left[\begin{array}{lll}30 & 35 & 42\end{array}\right]$} \\
\hline & & Very high & $>45$ & {$\left[\begin{array}{lll}40 & 45 & 50\end{array}\right]$} \\
\hline \multirow[t]{4}{*}{6.} & \multirow[t]{4}{*}{ Rainfall (mm) } & Low & $<600$ & {$\left[\begin{array}{lll}0 & 250 & 650\end{array}\right]$} \\
\hline & & Medium & $600-1200$ & {$\left[\begin{array}{llll}500 & 820 & 1200\end{array}\right]$} \\
\hline & & High & $1201-1800$ & {$\left[\begin{array}{llll}1100 & 1500 & 1900\end{array}\right]$} \\
\hline & & Very high & $>1800$ & {$\left[\begin{array}{llll}1700 & 2000 & 2500\end{array}\right]$} \\
\hline \multirow[t]{5}{*}{7.} & \multirow{5}{*}{$\begin{array}{l}\text { Future pavement condition } \\
\text { (FPC) }\end{array}$} & Very poor & $<25$ & {$\left[\begin{array}{lll}0 & 15 & 25\end{array}\right]$} \\
\hline & & Poor & $25-45$ & {$\left[\begin{array}{lll}20 & 35 & 50\end{array}\right]$} \\
\hline & & Fair & $46-65$ & {$\left[\begin{array}{llll}40 & 50 & 65\end{array}\right]$} \\
\hline & & Good & $66-81$ & {$\left[\begin{array}{lll}60 & 70 & 87\end{array}\right]$} \\
\hline & & Excellent & $>81$ & {$\left[\begin{array}{lll}80 & 90 & 100\end{array}\right]$} \\
\hline
\end{tabular}

